\title{
The Aggregate Matching Function and Job Search from Employment and Out of the Labor Force
}

\author{
Petr Sedláček
}

University of Bonn *

March 1, 2016

\begin{abstract}
The majority of new jobs in the U.S. is filled by workers coming from employment or from out of the labor force (inactivity). Yet, because the number of job seekers in these groups is unobserved, they are often ignored in empirical labor market studies. This paper, instead, uses latent-variable techniques to estimate the aggregate matching function - a relation between hires, vacant jobs and job seekers - while considering searchers from unemployment, employment and inactivity. Importantly, the estimation allows for the (match) efficiency with which these three groups of searchers find jobs to vary on average and over time. This paper finds that almost half of the rise in U.S. unemployment during the Great Recession is explained by a drop in match efficiency of the unemployed. This contrasts sharply with previous studies which found match efficiency to be quantitatively unimportant.
\end{abstract}

Keywords: matching function, mismatch, estimation

JEL Codes: E24, E32, J64

*University of Bonn, Department of Economics, Adenauerallee 24-42, 53113 Bonn, e-mail: sedlacek@uni-bonn.de. 


\section{Introduction}

About three quarters of all new jobs in the U.S. are filled by workers coming from employment or by those who were formally counted as out of the labor force. These "nonunemployed" searchers compete with the unemployed for available jobs. Taking their behavior into account is, therefore, crucial for understanding unemployment fluctuations.

A popular way of parsing unemployment fluctuations is through the lens of the aggregate matching function. This function relates new hires (matches) to the number of job seekers and vacant jobs. Any systematic changes in hires which cannot be accounted for by fluctuations in the number of job seekers or vacancies are then attributed to changes in "matching efficiency" (or "mismatch"). Existing studies find that the contribution of changes in mismatch to unemployment fluctuations is at most 30 percent. ${ }^{1}$ This paper, instead, finds that the contribution of mismatch can be as high as 49 percent.

The reason for such a stark difference in results is an omitted variable bias. Because job seekers from outside unemployment are unobserved, they are ignored in the vast majority of existing studies. This paper first shows analytically that such an omission is innocuous only if the numbers of unemployed and non-unemployed job seekers are perfectly correlated. If not, then estimates of the aggregate matching function and estimates of mismatch will be biased.

In order to quantify the bias, this paper proposes a state-space model of a generalized aggregate matching function which explicitly considers not only the unemployed, but also employed and inactive job seekers. Moreover, the (unobserved) degree of mismatch faced by job seekers from each of these labor market states is allowed to differ both on average and over time. The model is estimated with latent-variable techniques using U.S. monthly data from the end of 2000. The results suggest that on average around 40 percent of unemployment fluctuations over the business cycle can be attributed to fluctuations in matching efficiency. During the Great Recession, the contribution increased to as much as 49 percent. On the contrary, and in line with previous studies, estimating the model while ignoring non-unemployed job seekers results in a considerably lower contribution of mismatch. In such a case at most 23 percent of the increase in unemployment during the Great Recession can be accounted for by mismatch and much less during normal times.

The reason why ignoring the non-unemployed leads to dampened estimates of mismatch is that job seekers from outside unemployment are estimated to move pro-cyclically. For instance, this paper finds that the number of non-unemployed job seekers fell during the Great Recession. All else being equal, this lead to less crowding out in the labor market and made it relatively easier for the unemployed to find jobs. Ignoring this favorable

\footnotetext{
${ }^{1}$ See e.g. Barlevy (2011), Barnichon and Figura (forthcoming), Sahin, Song, Topa, and Violante (2014).
} 
effect biases the estimated increase in mismatch downwards, making it seem less severe than it actually was.

The identification of the unobserved degrees of mismatch faced by the three labor market groups is based on the assumption of random search. ${ }^{2}$ In particular, it can be shown that under random search the relative chances of finding a job from two different labor market states reflect the relative efficiencies with which individuals in these labor market groups find jobs. Therefore, using information on relative employment inflows from different labor market states in combination with data on total hires pins down the latent variables in the aggregate matching function.

At this point it is worth highlighting that mismatch in this paper is estimated as an unobserved, exogenous, component. However, there exists a range of reasons why mismatch may vary endogenously over time. ${ }^{3}$ The goal of this paper is not to extend the list of culprits. Rather, the goal is to use a rather standard methodology to estimate mismatch and show that extending it to account for job seekers from outside unemployment renders fluctuations in mismatch centrally important.

This paper relates to studies which estimate the role of mismatch in determining unemployment fluctuations. In an influential paper Sahin, Song, Topa, and Violante (2014) find that a rise in sectoral mismatch accounted for at most 30 percent of the unemployment rate increase during the Great Recession. Similar results can be found in e.g. Barlevy (2011); Barnichon and Figura (forthcoming); Dickens (2011); Lubik (2011); Sedláček (2014). The current paper also relates to studies estimating the aggregate matching function, a survey of which can be found in Petrongolo and Pissarides (2001). Recent papers include Borowczyk-Martins, Jolivet, and Postel-Vinay (2013); Hall (2005); Hornstein and Kudlyak (2015); Nagypál (2009); Rogerson and Shimer (2010). In contrast to all of the above, the current paper explicitly accounts for job seekers from outside unemployment. ${ }^{4}$

Non-unemployed job seekers have been included in matching function estimates in

\footnotetext{
${ }^{2}$ While the unemployed search by definition, this is not true for the stock of employed and inactive individuals. Therefore, their efficiency of matching is a combination of mismatch and the (unobserved and potentially time-varying) fraction of job seekers within these groups of individuals. Without independent evidence on job search, it is not possible to separate the latter two effects. Section 4.4 discusses the available evidence on search intensity and what it means for the estimated efficiency of matching.

${ }^{3}$ See e.g. Barnichon and Figura (forthcoming); Kuang and Valletta (2010); Sahin, Song, Topa, and Violante (2014); Sterk (2015); Sedláček (2014).

${ }^{4}$ In robustness exercises, Sahin, Song, Topa, and Violante (2014) attempt to control for job seekers from outside unemployment using imputed measures of (previous occupations of) discouraged workers and employed job seekers. However, discouraged workers account for only about 1 percent of all people outside the labor force. Furthermore, the imputed measure of employed job seekers is based on the American Time Use Survey which has a much smaller sample size and shorter timer period than the CPS (the authors therefore pool all years together and cannot investigate business cycle variation). Hornstein and Kudlyak (2015) investigate how ignoring unobserved search effort can lead to biased estimates of the matching function and mismatch.
} 
Boersma and van Ours (1999) and Jolivet (2009), neither of which, however, focuses on mismatch fluctuations. ${ }^{5}$ Veracierto (2011) measures mismatch in a standard matching model extended for job seekers from inactivity, but not from employment. Finally, in parallel to this paper, Hall and Schulhofer-Wohl (2013) estimate mismatch while considering employed and inactive job seekers. Reassuringly, despite their different methodology, they find that higher mismatch accounted for about 40 percent of the unemployment increase during the Great Recession. Their results are based on an overall mismatch index constructed from separate mismatch estimates for nine groups of job seekers categorized by their labor market state.

The rest of the paper is structured as follows. Section 2 discusses the basic concepts and analytically shows how estimates of the matching function are affected by disregarding non-unemployed job seekers. Section 3 lays out the proposed time-series model of a generalized matching function and describes the data. Section 4 presents the estimation results of the matching function and quantifies the impact match efficiency of the unemployed has on the unemployment rate. Finally, Section 5 provides some concluding remarks.

\section{Motivation and basic concepts}

Workers have many distinct features making them particularly suitable for certain tasks. Jobs too differ in their requirements and employers are not indifferent about which type of worker they hire. Therefore, searching for jobs on the one hand and looking for a suitable worker for a given vacancy on the other are time-consuming and costly processes.

The so-called matching function is meant to concisely capture the underlying heterogeneities, information imperfections, slow mobility, congestion effects and other factors which influence the creation of jobs. It links the number of newly created jobs $\left(H_{t}\right)$ to the number of job seekers $\left(S_{t}\right)$ and vacancies $\left(V_{t}\right)$ :

$$
H_{t}=h\left(S_{t}, V_{t}\right)
$$

where the function $h($.$) is assumed to be increasing, concave and often also linearly$ homogeneous in both of its arguments. Empirical studies have typically found support for these assumptions (see e.g. Petrongolo and Pissarides, 2001).

The number of job seekers in employment and outside the labor force is not observable. Therefore, the vast majority of empirical studies estimate the matching function using

\footnotetext{
${ }^{5}$ While Boersma and van Ours (1999) approximate the stock of non-unemployed job seekers with several simple statistics, similar to the current paper Jolivet (2009) uses relative employment inflows from non-unemployment to determine the share of non-unemployed job seekers.
} 
Figure 1: Flows into employment as a fraction of total hires

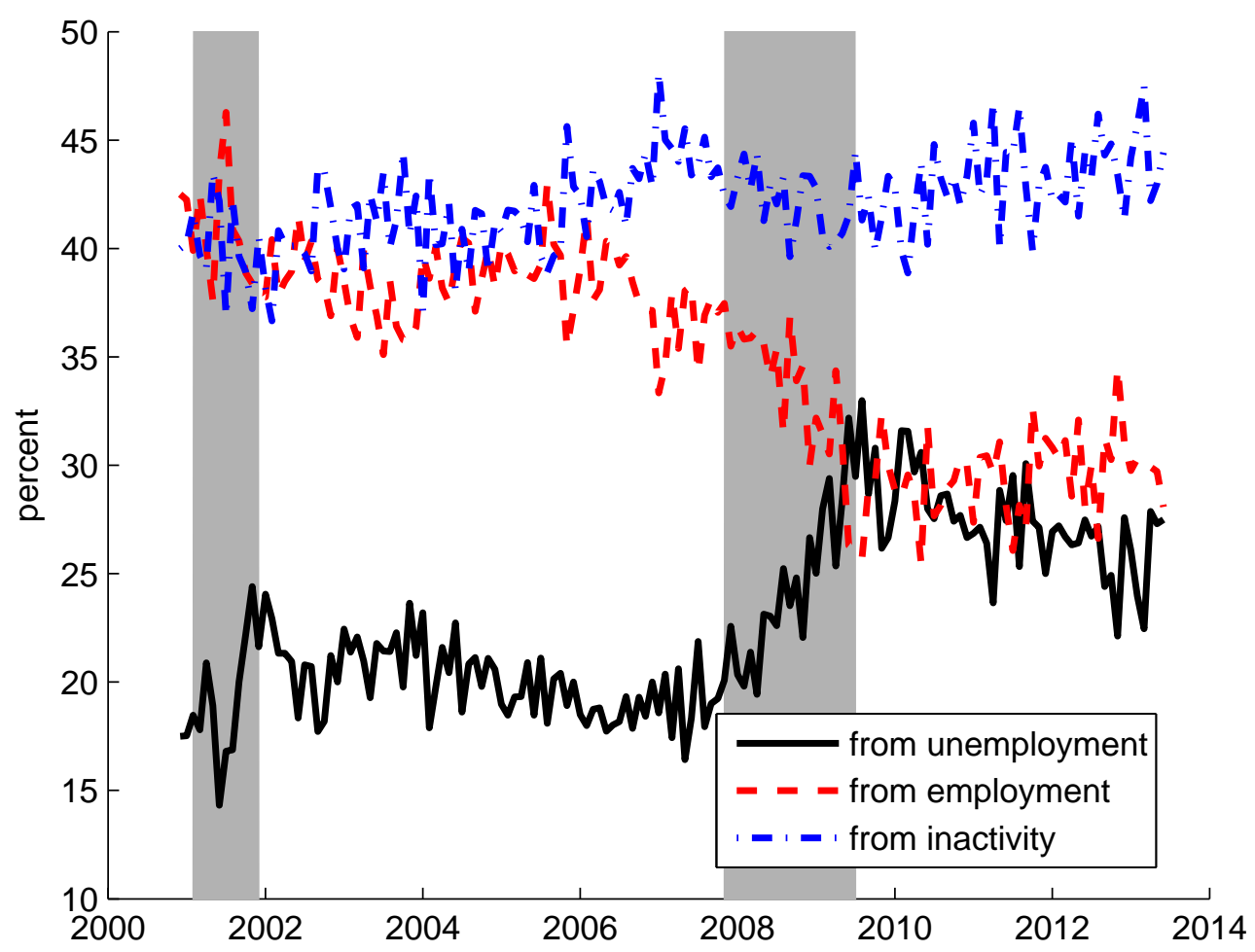

Notes: The figure shows flows from different labor market states (unemployment, employment and inactivity) into employment as a fraction of total flows. Shaded areas depict NBER recessions. Source: CPS.

only the number of unemployed as a proxy for total job seekers. However, as will be shown analytically in the next subsection, this approach is appropriate only if the numbers of unemployed and non-unemployed job seekers are perfectly correlated over the business cycle. In such a case, the shares of newly created jobs filled by each of the groups of job seekers would be expected to be constant over time. ${ }^{6}$ Figure 1 clearly shows that this is not the case. This suggests that estimating the matching function using only the unemployed as job seekers may lead to biased estimates.

\subsection{Matching function with(out) non-unemployed job seekers}

This subsection shows analytically how parameters of the aggregate matching function are affected by failing to take into account job seekers from outside unemployment. Towards this end, I consider a special case of the aggregate matching function. In particular, as in the vast majority of the literature, it is assumed that the aggregate matching function

\footnotetext{
${ }^{6}$ The shares would be exactly constant under the assumption of random search. In such a case the number of jobs filled by a given group of searchers is proportional to their share in the total number of job seekers.
} 
is of the Cobb-Douglas form with constant returns to scale:

$$
H_{t}=M_{t} S_{t}^{\mu} V_{t}^{1-\mu}
$$

where $M_{t}$ is a potentially time-varying scaling parameter referred to as matching efficiency or mismatch and $\mu$ is the elasticity of new hires with respect to job seekers. Assume also that the total number of job seekers consists of two groups of searchers. Those coming from unemployment, denoted $U_{t}$, and those coming from outside unemployment (i.e. from employment and inactivity), denoted $O_{t}$. Finally, assume that the number of job seekers from outside unemployment is known. Note also that in this specification, all job seekers face the same matching efficiency.

Consider the case when (2) describes the true data generating process for newly created jobs, but we omit job seekers from outside unemployment from the analysis. As was shown already by Boersma and van Ours (1999) the elasticity of hires with respect to only unemployed job seekers can then be written as:

$$
\mu^{b}=\frac{\partial H}{\partial U} \frac{U}{H}=\mu \frac{U+\epsilon_{O, U} O}{S},
$$

where $\epsilon_{O, U}=\frac{\partial O}{\partial U} \frac{U}{O}$ is the elasticity of non-unemployed job seekers with respect to searchers from unemployment. ${ }^{7}$ Therefore, unless $\epsilon_{O, U}$ is exactly equal to one, $\mu^{b}$ will be different from the elasticity of hires with respect to all job seekers $\mu$.

Next, let us inspect the effect of ignoring non-unemployed job seekers on the cyclicality of matching efficiency. Log-linearizing the true aggregate matching function in (2) and its counterpart which uses only the unemployed as job seekers it is possible to write

$$
\widehat{M}_{t}^{b}=\widehat{M}_{t}+\mu \frac{O}{S}\left(\widehat{O}_{t}-\widehat{U}_{t}\right)+\left(\mu^{b}-\mu\right)\left(\widehat{V}_{t}-\widehat{U}_{t}\right)
$$

where hats denote log-deviations from trend. In the above, $\widehat{M}_{t}$ denotes the true fluctuations in matching efficiency. Therefore, fluctuations in match efficiency based on ignoring non-unemployed job seekers, $\widehat{M}_{t}^{b}$, will be equal to the true variation in $\widehat{M}_{t}$ only if nonunemployed job seekers move one-for-one with unemployed searchers. ${ }^{8}$

It is perhaps natural to expect that the number of job seekers from outside unemployment co-moves with unemployed searchers but to a lesser extent, i.e. $0<\epsilon_{O, U}<1$. In this case both additional terms in the right-hand-side of (4) are negative indicating that fluctuations in $M_{t}^{b}$ are dampened compared to the true variation in $M_{t}$.

\footnotetext{
${ }^{7}$ Note, however, that this elasticity may in reality vary over time.

${ }^{8}$ Note that even if $\epsilon_{O, U}=1$ and thus $\mu^{b}=\mu$ it may still be the case that $\widehat{M}_{t}^{b}-\widehat{M}_{t} \neq 0$. This can happen if there are forces affecting $\widehat{O}_{t}$ which are, however, orthogonal to $\widehat{U}_{t}$.
} 


\section{Time-series model and data}

The previous section showed that ignoring job seekers from employment and inactivity has an effect on the value of the elasticity of hires with respect to job seekers and on the cyclicality of matching efficiency. In order to quantify the extent of these effects, this section proposes an unobserved components model of a generalized aggregate matching function which includes job seekers from outside unemployment. It will be made clear that the more common specification found in the literature, which omits non-unemployed job seekers, is a special case of the proposed generalized matching function.

\subsection{Accounting for non-unemployed job seekers}

Let us start by allowing the total number of job seekers to include not only the unemployed $\left(U_{t}\right)$, but also employed workers $\left(E_{t}\right)$ and those which are economically inactive $\left(I_{t}\right)$. However, while all unemployed search for jobs by definition, the number of job seekers in employment and out of the labor force is unobserved. Let us denote the unobserved fractions of job seekers among the employed and inactive by $v_{t}^{E}$ and $v_{t}^{I}$, respectively. Moreover, job seekers from different labor market states may face different degrees of mismatch, denoted by $M_{t}^{U}, M_{t}^{E}$ and $M_{t}^{I}$ for the unemployed, employed and inactive, respectively. ${ }^{9}$

Without independent evidence on the fraction of searchers in the group of nonunemployed, it is impossible to separate the effects of changes in matching efficiencies from those stemming from changes in the fractions of searchers. ${ }^{10}$ Therefore, let us denote the product of the latter two $\Phi_{t}^{j}=M_{t}^{j} v_{t}^{j}$ as the fraction of "effective" job seekers among the employed and inactive, with $j=E, I$, respectively. The total number of effective job seekers is then defined by

$$
S_{t}=M_{t}^{U} U_{t}+\Phi_{t}^{E} E_{t}+\Phi_{t}^{I} I_{t}
$$

Under the assumption of constant returns to scale the aggregate matching function can then be written as $^{11}$

$$
H_{t}=\left(M_{t}^{U} U_{t}+\Phi_{t}^{E} E_{t}+\Phi_{t}^{I} I_{t}\right)^{\mu} V_{t}^{1-\mu}
$$

Factoring out $M_{t}^{U}$ allows for the popular interpretation of matching efficiency of the

\footnotetext{
${ }^{9}$ These may arise because of differences in average search intensity, but also e.g. because of a different education/skill composition or geographical location of the respective pools of job seekers.

${ }^{10}$ In principle the unemployed may also search with different intensity. Section 4.4 discusses the available evidence on search intensity and what it means for the estimated matching efficiencies.

${ }^{11}$ The online Appendix shows that the results are robust to relaxing the assumption of constant returns to scale.
} 
unemployed as residual variation in hires not attributable to fluctuations in vacancies or the number of job seekers. In particular, equation (6) can be rewritten as

$$
H_{t}=\widetilde{M}_{t}\left(U_{t}+\frac{\Phi_{t}^{E}}{M_{t}^{U}} E_{t}+\frac{\Phi_{t}^{I}}{M_{t}^{U}} I_{t}\right)^{\mu} V_{t}^{1-\mu}
$$

where $\widetilde{M}_{t}^{1 / \mu}=M_{t}^{U}$. Notice, however, that in (7) changes in match efficiency of the unemployed have not only a direct effect on total hires, but also an indirect effect through fluctuations in the number of effective job seekers.

The proposed generalized matching function is characterized by three latent variables: $M_{t}^{U}, \Phi_{t}^{E}$ and $\Phi_{t}^{I}$. In order to identify these unobserved states, the state-space model will follow the literature on random search and make use of its implications for the breakdown of total hires into flows from the three labor market states. In particular, under random search unemployment-to-employment flows $\left(H_{t}^{U}\right)$, employment-to-employment transitions $\left(H_{t}^{E}\right)$ and hires from inactivity $\left(H_{t}^{I}\right)$ are all proportional to total hires. The factors of proportionality are the respective shares of job seekers in the total number of effective searchers (i.e. the probabilities that a newly hired worker comes from the respective labor market states). Specifically, worker flows into employment can be expressed as follows:

$$
\begin{aligned}
H_{t}^{U} & =\frac{M_{t} U_{t}}{S_{t}} H_{t}, \\
H_{t}^{E} & =\frac{\Phi_{t}^{E} E_{t}}{S_{t}} H_{t}, \\
H_{t}^{I} & =\frac{\Phi_{t}^{I} I_{t}}{S_{t}} H_{t} .
\end{aligned}
$$

In principle, the above three equations together with the definition of the aggregate matching function in (6) can be used for estimation. ${ }^{12}$ However, it is convenient to work with a reduced state-space system which also better highlights the sources of identification of the unobserved states discussed in detail in Section 3.3. In particular, we can divide equations (9) and (10) by equation (8). This results in two expressions linking the relative sizes of employment inflows, $\frac{H_{t}^{E} / E_{t}}{H_{t}^{U} / U_{t}}\left(\frac{H_{t}^{I} / I_{t}}{H_{t}^{U} / U_{t}}\right)$, to the respective relative magnitudes of the unobserved variables, $\Phi_{t}^{E} / M_{t}^{U}\left(\Phi_{t}^{I} / M_{t}^{U}\right)$. Together with the definition of the aggregate

\footnotetext{
${ }^{12}$ The online Appendix shows that such a specification delivers almost identical results to the benchmark.
} 
matching function in (6) we obtain our benchmark state-space system:

$$
\begin{aligned}
h_{t} & =\mu \ln \left(M_{t}^{U} U_{t}+\Phi_{t}^{E} E_{t}+\Phi_{t}^{I} I_{t}\right)+(1-\mu) v_{t}+\epsilon_{t}^{h} \\
h_{t}^{E} & =\phi_{t}^{E}-m_{t}^{U}+e_{t}-u_{t}+h_{t}^{U}+\epsilon_{t}^{e} \\
h_{t}^{I} & =\phi_{t}^{I}-m_{t}^{U}+i_{t}-u_{t}+h_{t}^{U}+\epsilon_{t}^{i} \\
m_{t}^{U} & =m_{t-1}^{U}+\eta_{t}^{u}, \\
\phi_{t}^{E} & =\phi_{t-1}^{E}+\eta_{t}^{e}, \\
\phi_{t}^{I} & =\phi_{t-1}^{I}+\eta_{t}^{i},
\end{aligned}
$$

where lower-case letters denote natural logarithms of variables. The specification of the three unobserved states follows the literature on time-varying coefficients (see e.g. Cogley and Sargent, 2005; Primiceri, 2005). ${ }^{13}$ Finally, measurement errors and innovations to the unobserved states are assumed to be distributed as $\epsilon_{t}=\left(\epsilon_{t}^{h}, \epsilon_{t}^{u}, \epsilon_{t}^{e}\right)^{\prime} \sim N(0, R)$ and $\eta=\left(\eta_{t}^{u}, \eta_{t}^{e}, \eta_{t}^{i}\right)^{\prime} \sim N(0, Q)$, with $\mathbb{E}\left[\epsilon_{t} \eta_{t}^{\prime}\right]=0$ for all $t .^{14}$

\subsection{Ignoring non-unemployed job seekers}

Notice that the more common specification in the literature in which non-unemployed job seekers are ignored is simply a special case of (6) when $\Phi_{t}^{E}=\Phi_{t}^{I}=0$ (i.e. when the fraction of job seekers in the two labor market states is zero). Denoting again natural logarithms by lower-case letters, the resulting state-space system can be written as:

$$
\begin{aligned}
h_{t} & =\mu^{b} m_{t}^{b}+\mu^{b} u_{t}+\left(1-\mu^{b}\right) v_{t}+\epsilon_{t}^{b}, \\
m_{t}^{b} & =m_{t-1}^{b}+\eta_{t}^{b},
\end{aligned}
$$

where the measurement error and the state innovation are assumed be distributed as $\epsilon_{t}^{b} \sim N\left(0, R^{b}\right)$ and $\eta_{t}^{b} \sim N\left(0, Q^{b}\right)$, respectively, with $\mathbb{E}\left[\epsilon_{t}^{b}, \eta_{t}^{b \prime}\right]=0$. The above system can be estimated by using either total hires or employment inflows from unemployment as the dependent variable. Notice, however, that both cases are misspecified because the former assigns all hires while the latter assigns all available vacancies to unemployed job seekers alone. In what follows, results from the benchmark model in (11) will be compared to those from the special case in (12) estimated both on total hires and unemployment-toemployment flows as the dependent variable.

\footnotetext{
${ }^{13}$ The online Appendix shows that assuming an AR(p) specification instead changes little.

${ }^{14}$ The online Appendix shows that allowing for a non-zero covariance between the state and observation innovations changes little.
} 


\subsection{Identification}

Before moving on, it is instructive to discuss in more detail the identification of the three latent variables $\left(M^{U}, \Phi^{E}, \Phi^{I}\right)$ within the benchmark state-space model. The key in this respect is the widely used assumption of random search and in particular its implications for the breakdown of total hires into employment inflows from the three labor market states.

First, let us focus on the second and third observation equations in the benchmark model (11). Collecting latent variables on one side and data on the other, these two equations state that the fraction of the latent variables $\frac{\Phi^{E}}{M^{U}}\left(\frac{\Phi^{I}}{M^{U}}\right)$ is pinned down by systematic variation in the related ratios of job finding probabilities $\frac{H^{E} / E}{H^{U} / U}\left(\frac{H^{I} / I}{H^{U} / U}\right)$. In other words, under random search the relative chances of finding a job from different labor market states reflect the relative efficiencies with which the stock of unemployed, employed or inactive workers find jobs.

Second, having identified the relative magnitudes of the unobserved variables, information on total hires together with the structure of the aggregate matching function pins down their levels. In particular, as was discussed earlier in the context of (7), matching efficiency of the unemployed can be "factored out" to have the interpretation of residual variation in hires not attributable to changes in vacancies or the number of (effective) job seekers. Given the evolution of the ratios $\frac{\Phi^{E}}{M^{U}}$ and $\frac{\Phi^{I}}{M^{U}}$, the first equation in (11) will attribute any systematic residual variation in hires to $M^{U}$.

Finally, notice that if one assumes away measurement error in the second and third observation equations in (11), it is possible to estimate the model with $M_{t}^{U}$ as the only unobserved state. The other two latent variables are thus essentially forced to follow the (quite volatile) data on relative job finding rates. The online Appendix shows that such a specification leads to results which are similar to the benchmark but which violate the assumptions of no serial correlation of the forecast errors.

\subsection{Data}

Worker flows into employment from all three labor market states (the sum of which defines total hires) are taken from the CPS as are the stocks of unemployed, employed and inactive individuals. ${ }^{15}$ Vacancies are taken from the Job Openings and Labor Turnover

\footnotetext{
${ }^{15}$ Total worker flows into employment in the CPS do not add up to the "hires" variable in JOLTS (the former is almost double of the latter and is two thirds as volatile as the latter). Davis, Faberman, Haltiwanger, and Rucker (2008) show that part of this can be attributed to a lack of establishment openings and very young establishments and to the treatment of non-respondents in the JOLTS data. The authors also find that these issues are not so severe for the job openings variable in JOLTS. Nevertheless, the online Appendix shows that the results are even starker when using the JOLTS total hires variable instead of the sum of worker flows into employment from the CPS.
} 
Survey (JOLTS) which offers monthly information covering the U.S. non-farm sector starting from December 2000. The job openings variable (vacancies) is a count of all positions that are open on the last day of the month. The sample period starts in December 2000 and finishes in June 2013.

Finally, following Borowczyk-Martins, Jolivet, and Postel-Vinay (2013) the estimation is based on seasonally unadjusted data and all three observation equations in (11) include month dummy variables to capture seasonality. ${ }^{16}$

\section{Estimation results}

This section presents the results of the benchmark model in (11). Note that this model is non-linear in the observation equations. The Maximum Likelihood estimation is therefore based on the Extended Kalman filter. ${ }^{17,18}$

The following paragraphs first present the estimated time-paths of the number of job seekers from the three labor market states, showing that the cyclical properties of the unemployed are different from the other two groups of job seekers. As Section 2.1 showed, in this case omitting non-unemployed job seekers from the analysis will affect the estimates of the matching elasticity and the extent of mismatch fluctuations. Second, this section reports the estimates of the matching function both under the benchmark specification and under the case when non-unemployed job seekers are ignored. Third, it quantifies what the estimated pattern of mismatch implies for unemployment rate fluctuations. Finally, this section also investigates to what extent the estimated timepaths of match efficiency can be linked to changes in the search behavior of the respective groups of job seekers.

\subsection{Estimates of the number of job seekers}

Figure 2 shows the number of unemployed and the estimated number of employed $\left(\Phi^{E} E\right)$ and inactive job seekers $\left(\Phi^{I} I\right)$. The latter two are shown with their respective onestandard-deviation confidence bands implied by the uncertainty about the estimates of

\footnotetext{
${ }^{16}$ The online Appendix shows that the results are robust to alternative ways of seasonal adjustment. Not adjusting for seasonality, however, results in the regression residuals violating the assumptions of normality and no serial correlation.

${ }^{17}$ The Extended Kalman filter essentially linearizes the state-space system at each point in time and applies the regular Kalman filter recursions. The details of the filter are presented in the online Appendix. Using Monte Carlo simulations, the online Appendix also shows that the estimation performs very well in identifying the unobserved states and the matching elasticity.

${ }^{18}$ Strictly speaking, the estimation is one of Quasi-Maximum Likelihood, because the extended Kalman filter uses a first-order approximation to the true non-linear state-space system. However, the online Appendix shows that the null hypothesis of normality, homoscedasticity and no serial correlation of the estimated normalized forecast errors cannot be rejected at conventional levels of significance.
} 
Figure 2: Job seekers from (un-)employment and inactivity

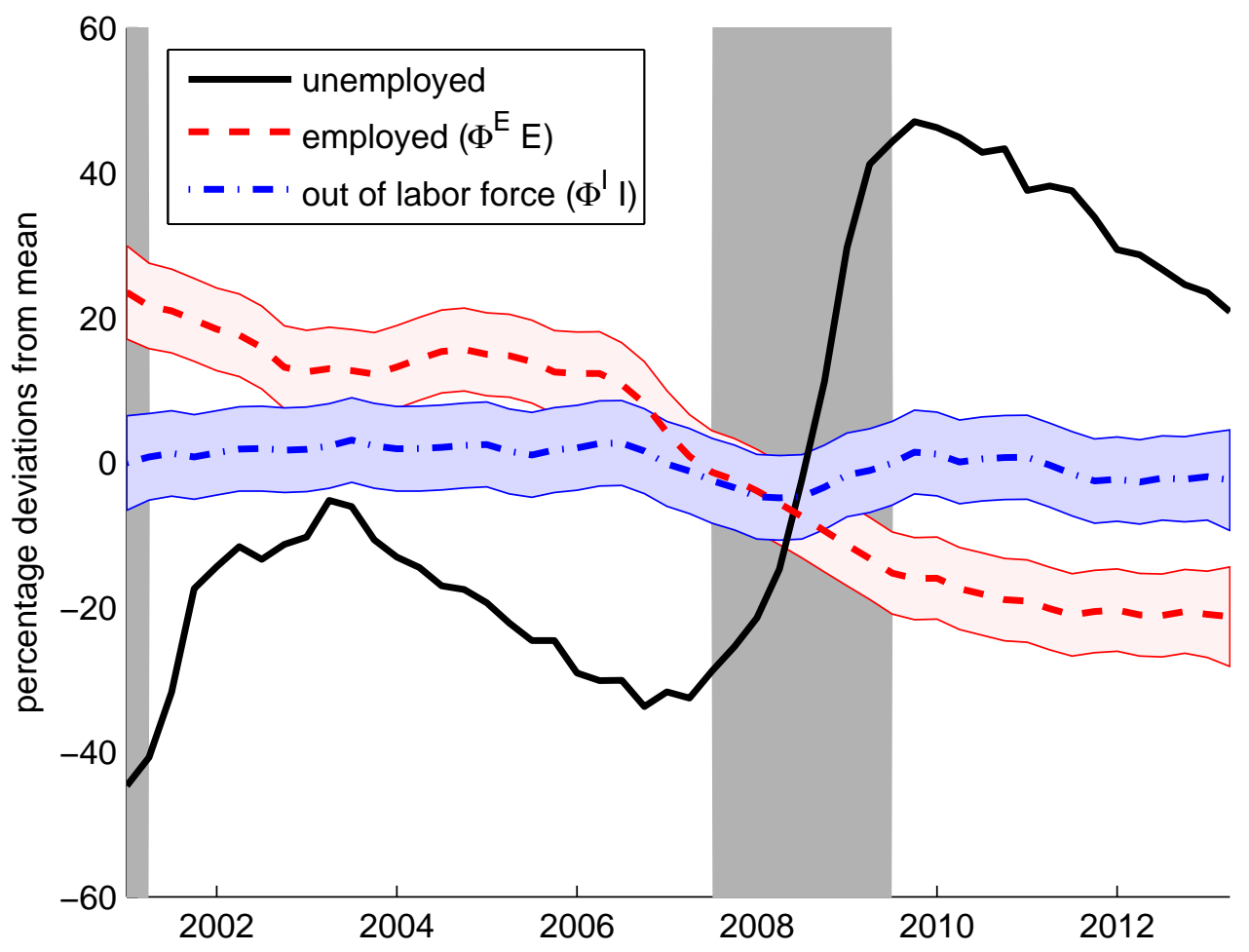

Notes: quarterly averages of the number of unemployed and the estimated numbers of employed and inactive job seekers in percent deviations from their respective means. The estimated number of job seekers from employment and inactivity are shown together with their one-standard-deviation confidence bands (based on uncertainty about $\Phi^{E}$ and $\Phi^{I}$, respectively) which are indicated by shaded areas around the respective point estimates. The vertical shaded areas indicate NBER recessions.

$\Phi^{E}$ and $\Phi^{I}$, respectively. Clearly, non-unemployed job seekers have different cyclical properties from the unemployed. While the latter increased at the onset of the Great Recession, the former two dropped.

The number of job seekers from inactivity fell by about 5 percent in the latest downturn. However, since 2009 they have fully recovered and were back at their sample average before the end of the crisis. The end of this section will discuss how this particular pattern can be related to certain groups of inactive workers, namely the marginally attached and discouraged workers.

On the contrary, the number of employed job seekers experienced a severe drop which started prior to the recent crisis and which seems not to have recovered even in $2013 .{ }^{19}$

As was pointed out earlier, if fluctuations in the number of all job seekers are different

\footnotetext{
${ }^{19}$ Interestingly, similar to the estimated number of employed job seekers, the quit rate (i.e. the number of quits relative to the number of employed) was also about $20 \%$ above (below) its average at the beginning (end) of the sample (the correlation coefficient between the two time-series is 0.85). Although this is in line with the notion that $\Phi_{t}^{E}$ is picking up the extensive margin of search, a structural model would be needed to confirm this conclusion because the quit rate itself is likely to be endogenously responding to a lower matching efficiency.
} 
from those of the unemployed, as the estimates above suggest, then ignoring job seekers from outside unemployment will affect the estimates of the matching function. The next subsections therefore compare estimates of the matching elasticity and of mismatch from the benchmark model and from models which ignore non-unemployed job seekers. They also quantify what these estimates imply for our understanding of the sources of unemployment rate fluctuations.

\subsection{Estimates of the aggregate matching function}

The elasticity of newly created jobs with respect to job seekers is estimated at 0.76 with a standard error of 0.031. This is at the higher end of estimates found in studies which ignore non-unemployed job seekers (see e.g. Petrongolo and Pissarides, 2001).

Table 1 reports estimates of the matching elasticity from the benchmark model and for two specifications in which non-unemployed job seekers are ignored in the estimation. The first uses total hires $(H)$, while the second uses unemployment-to-employment flows $\left(H^{U}\right)$ as dependent variables in the estimation of model (12). ${ }^{20}$ The table also compares these estimates with values found in existing studies. Encouragingly, the latter two estimates are very close to results found in the existing literature.

In particular, the estimate of the matching elasticity based on total hires (0.34), is virtually identical to the results obtained in Sahin, Song, Topa, and Violante (2014) and very close to Borowczyk-Martins, Jolivet, and Postel-Vinay (2013), who use the same data, but slightly shorter sample periods. ${ }^{21}$ The estimate also falls within the values found in Hall (2005), 0.23, and Nagypál (2009), 0.47, who use the JOLTS total hires data and consider only unemployed job seekers in a simple OLS regression. ${ }^{22}$

The elasticity estimate based on unemployment-to-employment flows (0.68) is also practically identical to that found in Sahin, Song, Topa, and Violante (2014). Barnichon and Figura (forthcoming) find a value of 0.66 using the CPS unemployment-employment flows and the vacancy index constructed by Barnichon (2010) over the years 1976-2012. ${ }^{23}$ Rogerson and Shimer (2010) find a value between 0.58 and 0.72 , based on a job finding rate constructed according to Shimer (2005) and vacancy data from JOLTS (ranging from 2001-2009) or vacancy data from the Conference Board (ranging from 1951-2003),

\footnotetext{
${ }^{20}$ In the case of ignoring non-unemployed job seekers, total hires are taken from the JOLTS database for comparability with previous studies. The estimate of the matching elasticity when total hires from the CPS are used instead (as in the benchmark model) is 0.48 with a standard error of 0.03 .

${ }^{21}$ Similarly in spirit to the current paper, Sahin, Song, Topa, and Violante (2014) estimate the matching function while modeling match efficiency with time-varying polynomials and structural breaks.

${ }^{22}$ Hall's estimate is based on a single year of data (2002), while Nagypál's value is based on the sample period 2001-2004.

${ }^{23}$ The authors also use a two-stage procedure to account for labor market heterogeneity and find a value of 0.82 .
} 
Table 1: Matching elasticity estimates

\begin{tabular}{ccc}
\hline & dependent variable \\
$H$ & $H^{U}$ \\
\hline
\end{tabular}

benchmark

this paper

0.76

$(0.03)$

ignoring non-unemployed job seekers

0.34

0.68

$(0.02)$

other studies

Barnichon and Figura (forthcoming)

0.66

Borowczyk-Martins, Jolivet, and Postel-Vinay (2013)

0.31

Hall (2005)

0.23

Nagypál (2009)

0.47

Rogerson and Shimer (2010)

0.34

0.72

Sahin, Song, Topa, and Violante (2014)

0.69

Sedláček (2014)

0.57

Notes: The top panel of the table reports point estimates of the matching elasticity with respect to job seekers in the "benchmark" model and in the models "ignoring non-unemployed job seekers". Standard errors are shown in brackets. The bottom panel reports estimates from other studies grouped by their respective dependent variables.

respectively. Finally, Sedláček (2014) uses Shimer's job finding rate and real GDP data within a simple search and matching model and obtains an elasticity estimate of 0.57 for the period between 1948 and 2011.

\subsection{Matching efficiency of the unemployed}

In recent years, the topic of mismatch of the unemployed has received an increased amount of attention, both in academic and in policy circles. ${ }^{24}$ One motivating factor was the persistently high unemployment rate following the Great Recession. Existing studies, however, came to a consensus that increased mismatch is unlikely to be a major driver of the observed unemployment rate increase during the latest downturn.

This subsection revisits the question in light of the benchmark model which explicitly considers job seekers from outside unemployment. Figure 3 shows (Kalman-smoothed) estimates of matching efficiency from the benchmark model and from the two specifications which ignore non-unemployed job seekers. While all match efficiency estimates decline in the Great Recession, the strongest fall is estimated in the benchmark model. Specifically, the drop during the Great Recession is $2.1-5.8$ times as large in the bench-

\footnotetext{
${ }^{24}$ In what follows match efficiency or mismatch always refers to that of the unemployed, unless stated otherwise.
} 
Figure 3: Match efficiency of the unemployed: different specifications

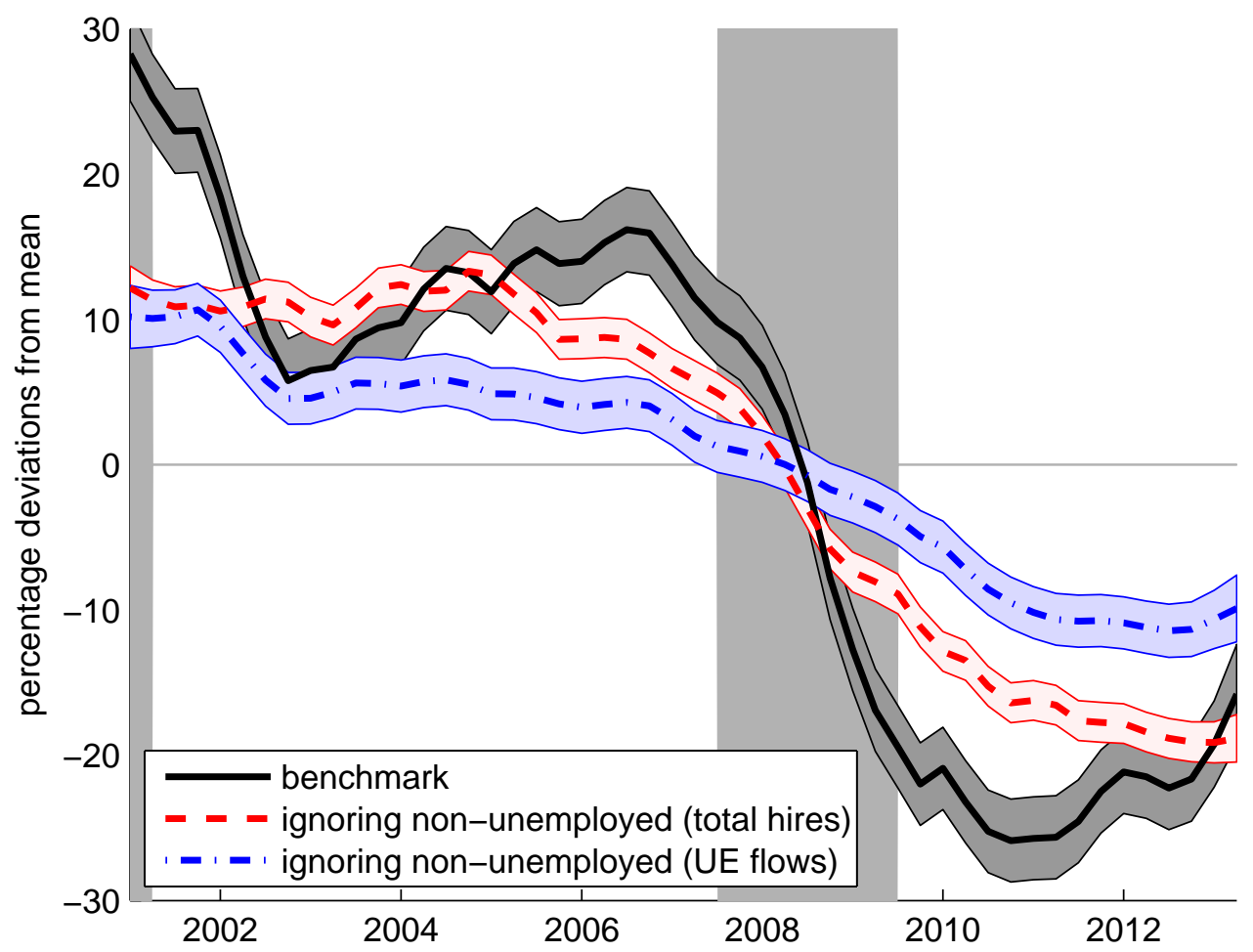

Notes: quarterly averages of estimates of match efficiency based on three specifications': the "benchmark" specification from (11), and two estimates ignoring non-unemployed job seekers based on (12) using either "total hires" or only unemployment to employment ("UE") flows. All estimates are expressed in $\log$ deviations from their respective means and are shown together with $90 \%$ confidence bands which are indicated by shaded areas around the respective point estimates. The vertical shaded areas depict NBER recessions.

mark model compared to the cases when the non-unemployed job seekers are ignored. In all three cases match efficiency keeps on dropping even after the crisis finishes but the benchmark model suggests that match efficiency reverted back around 2011.

The reason for why the benchmark model estimates a stronger drop in matching efficiency is relatively intuitive. The estimation results show that the number of job seekers from outside unemployment declined during the Great Recession (see Figure 2). Therefore, all else equal, it became easier for the unemployed to find jobs as competition on the labor market lessened. If this beneficial effect is not taken into account it is absorbed in the estimate of matching efficiency which is then characterized by a less severe drop.

\subsubsection{Impact of match efficiency on average}

Although the previous paragraphs documented that ignoring non-unemployed job seekers results in an underprediction of the cyclicality of estimated match efficiency, it is not 
Table 2: Mismatch contributions to variation in job finding and unemployment rates $1^{\text {st }}$-diff. linear HP

\begin{tabular}{lrrr}
\hline A: job finding rate variation & & & \\
benchmark & 53.8 & 64.4 & 61.3 \\
ignoring non-unemployed (total hires) & 4.2 & 12.0 & 7.1 \\
ignoring non-unemployed (UE flows) & 3.3 & 10.4 & 7.5 \\
& & & \\
B: unemployment rate variation & & & \\
benchmark & 26.9 & 40.6 & 40.5 \\
ignoring non-unemployed (total hires) & 7.5 & 17.3 & 16.7 \\
ignoring non-unemployed (UE flows) & 1.4 & 7.0 & 6.8 \\
\hline
\end{tabular}

Notes: contributions (in percent of total variation) of estimated changes in match efficiency to variation in the job finding rate of the unemployed and the unemployment rate.

clear to what extent these differences matter quantitatively. This subsection therefore investigates the average impact match efficiency changes have on the job finding rate of the unemployed and on the unemployment rate. The next subsection then shows how important the decline in match efficiency was during the Great Recession.

Let us first decompose the variation of the job finding rate of the unemployed $\left(F_{t}=\right.$ $\left.H_{t}^{U} / U_{t}\right)$ into the (direct) contribution of matching efficiency and that of vacancies and the number of job seekers. ${ }^{25}$ From the definition of the job finding rate and using (8) we can write

$$
\operatorname{var}\left(\widehat{F}_{t}\right)=\operatorname{cov}\left(\widehat{F}_{t}, \widehat{M}_{t}^{U}\right)+(1-\mu) \operatorname{cov}\left(\widehat{F}_{t}, \widehat{V}_{t}-\widehat{S}_{t}\right)+\omega_{t}
$$

where hatted variables indicate log-deviations from trend and $\omega_{t}$ is a residual coming from the detrending method. Panel A of Table 2 reports the contribution of match efficiency to the variation in the job finding rate expressed in percent of total variance, i.e. $\frac{\operatorname{cov}\left(\widehat{F}_{t}, \widehat{M}_{t}^{U}\right)}{\operatorname{var}\left(\widehat{F}_{t}\right)} 100$. The variance decompositions are conducted for first differences, linear and HP-filter detrending. ${ }^{26}$

In the benchmark model the (average) contribution of match efficiency to job finding rate fluctuations is large: around 60 percent at business cycle frequencies. In contrast, the contribution is only between $8-12$ percent when the non-unemployed job seekers are ignored in the estimation.

A similar variance decomposition can be applied to the unemployment rate. Following Elsby, Michaels, and Solon (2009) the variance decomposition is based on the steady state relationship between the unemployment rate and the inflow and outflow rates from unemployment, i.e. $U_{t} / L_{t} \approx \frac{\Lambda_{t}}{\Lambda_{t}+F_{t}}$, where $L_{t}$ is the labor force and $\Lambda_{t}$ is the employment-

\footnotetext{
${ }^{25}$ Matching efficiency also impacts the job finding rate indirectly through its effect on the number of effective job seekers.

${ }^{26}$ The smoothing parameter of the HP filter is set to 129600 as suggested by Ravn and Uhlig (2002) for monthly data.
} 
to-unemployment flow rate. In particular, the unemployment rate can be expressed as

$$
\widehat{U_{t} / L_{t}} \approx\left(1-\overline{U_{t} / L_{t}}\right)\left(\widehat{\Lambda}_{t}-\widehat{F}_{t}\right)
$$

where hatted variables again denote log-deviations from trend and $\overline{U_{t} / L_{t}}$ denotes the trend of the unemployment rate in period $t$.

Panel B of Table 2 shows the percentage contributions of match efficiency changes to the variation in the unemployment rate. As with its contributions to the job finding rate, matching efficiency contributes considerably also to unemployment rate fluctuations. The average contribution is around 40 percent at business cycle frequencies. This contrasts with the relatively low contributions of $7-17$ percent when non-unemployed job seekers are not taken into account.

\subsubsection{Impact of match efficiency during the Great Recession}

The above values indicate that match efficiency changes contribute substantially to unemployment rate fluctuations on average over the sample period. The average numbers may, however, hide higher values in certain periods. Let us therefore inspect the role of match efficiency for the development of the unemployment rate during the Great Recession.

Figure 4 shows the actual unemployment rate during and in the aftermath of the Great Recession together with three counterfactual unemployment rates. Each of the counterfactuals was constructed by assuming that match efficiency remained constant at its level in November 2007, i.e. just before the official start of the recession. The differences between the counterfactuals stem from the way match efficiency was estimated, again considering the benchmark which incorporates job seekers from outside unemployment and the two alternatives which do not.

Consistent with previous studies, match efficiency contributed only moderately to the unemployment increase when non-unemployed job seekers are not taken into account (at most between 0.6 and 1.2 percentage points of unemployment). In other words, match efficiency explains at most about $23 \%$ of the unemployment rate increase after 2007 . This value is consistent with e.g. Barnichon and Figura (forthcoming), Sahin, Song, Topa, and Violante (2014) and Sedláček (2014).

The picture changes considerably when match efficiency is estimated while taking into account job seekers from outside unemployment. In this case, had the efficiency of matching remained at its pre-crisis level, the unemployment rate would have peaked at $7.6 \%$ instead of the observed $10 \%$. On average, during the Great Recession, the estimated fall in match efficiency accounts for $45 \%$ of the unemployment rate increase. The maximum contribution of match efficiency during this period is $49 \%$. The presented 
Figure 4: Unemployment rate: actual and counterfactuals

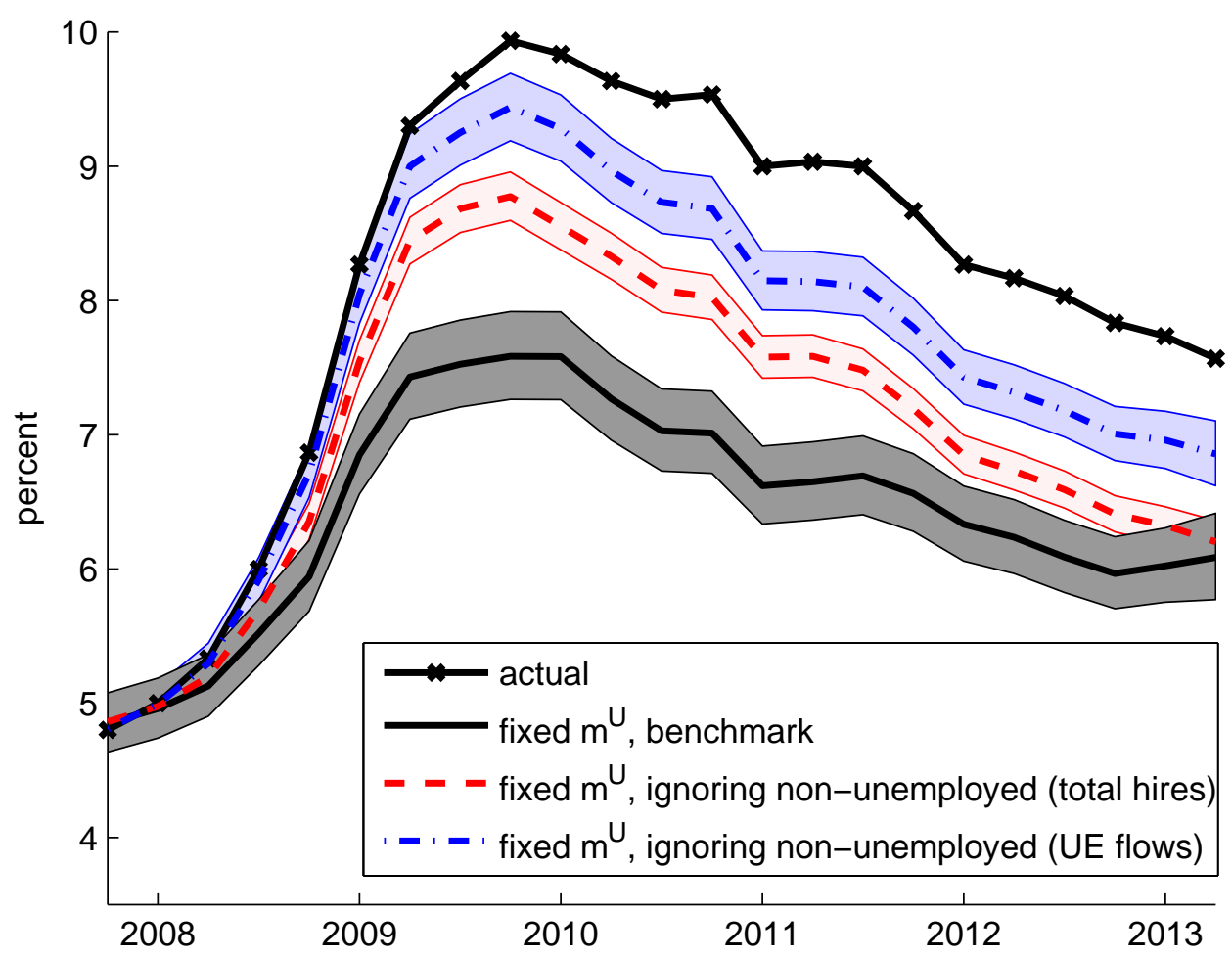

Notes: actual and the counterfactual unemployment rates based on the assumption that matching efficiency remains fixed at its level in November 2007. The three counterfactuals are based on the same specifications as in Figure 3. The shaded areas indicate confidence intervals based on the $90 \%$ errors bands of the respective matching efficiency estimates.

results therefore suggest that match efficiency fluctuations cannot be discarded as an important source of unemployment rate changes. ${ }^{27}$

Another way to visualize the impact of the decline in match efficiency during the Great Recession is to depict the Beveridge curve. Figure 5 shows the observed Beveridge curve which is characterized by the well-know outward shift during the Great Recession. The figure also plots a counterfactual Beverdige curve based on the results from the benchmark model and the assumption that match efficiency remains constant at its precrisis level. Had match efficiency not dropped as it did during the crisis, the Beveridge curve would have essentially experienced no outward shift and remained in line with its pre-crisis pattern.

\footnotetext{
${ }^{27} \mathrm{~A}$ concern may be that part of the estimated effect of mismatch on the unemployment rate is because of a secular decline in matching efficiency rather than because of a cyclical drop during the recession. This concern of course applies also to the case when job seekers from outside unemployment are not taken into account and therefore qualitatively the above results will not change. Quantitatively, the results are also almost unchanged. In particular, estimating a linear trend prior to 2007, extrapolating it to the end of the sample and redoing the above exercises (net of the trend component) results in the counterfactual unemployment rate peaking at $8.1 \%$ instead of $7.9 \%$.
} 
Figure 5: Beveridge curve: actual and counterfactual

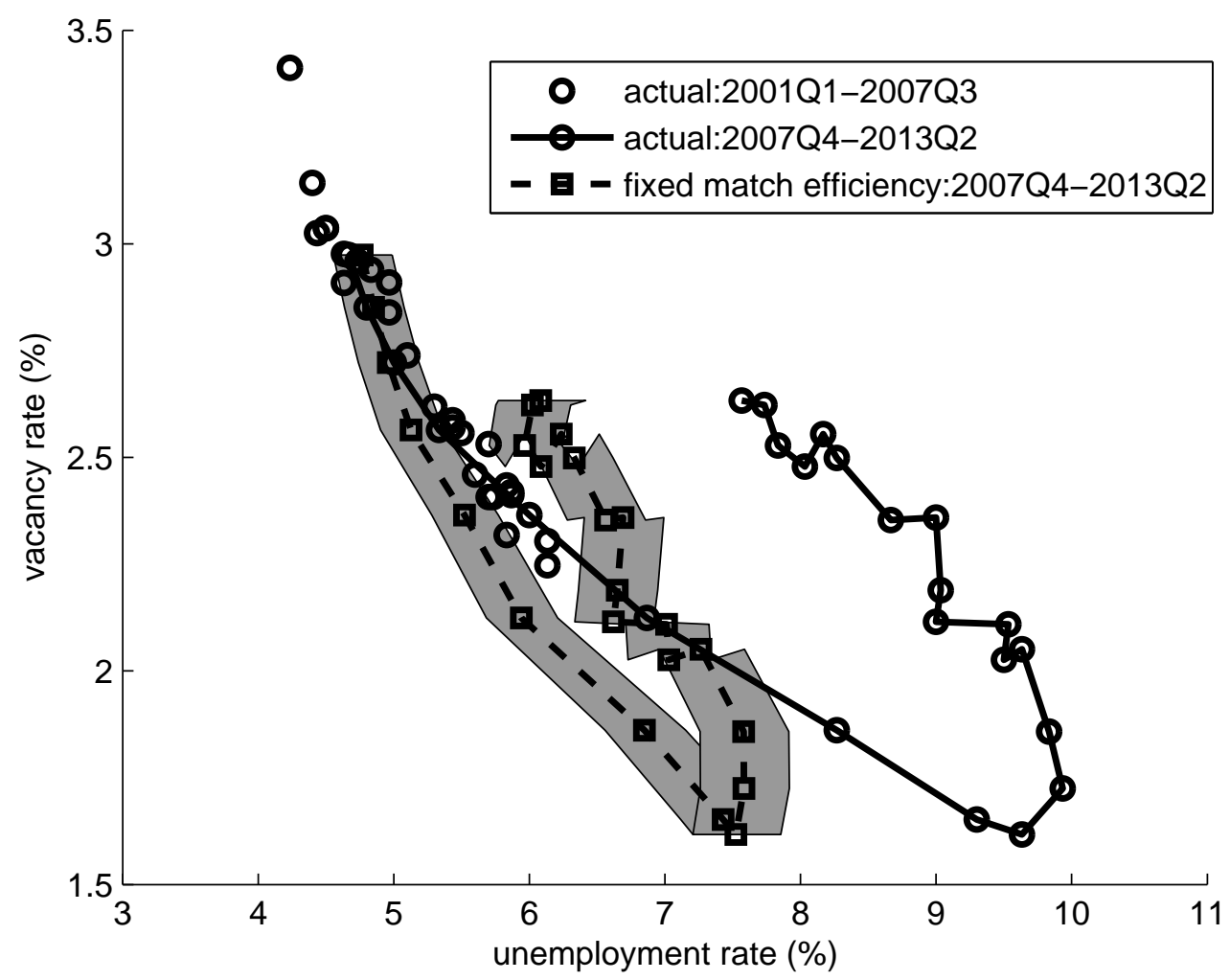

Notes: actual and the counterfactual Beveridge curve based on the assumption that match efficiency remains fixed at its level in November 2007. The shaded area indicates a confidence interval based on the $90 \%$ error bands of the benchmark matching efficiency estimate.

\subsubsection{Crowding out effect of non-unemployed job seekers}

Previous paragraphs showed that ignoring the non-unemployed has important effects on the estimates of the matching elasticity and efficiency. However, job seekers from outside unemployment also effect the job finding rate of the unemployed because they compete for the same jobs (i.e. they impose a crowding out effect on the unemployed).

From the matching function it can be shown that the elasticity of the job finding rate of the unemployed with respect to the number of non-unemployed job seekers is given by $\epsilon_{t}^{F, \Phi^{j} j}=(\mu-1) \frac{\Phi_{t}^{j} j_{t}}{S_{t}}<0$, where $j=E, I$. The elasticity is negative meaning that a drop in the number of job seekers from outside unemployment improves the chances of the unemployed finding jobs. On average over the sample, this elasticity is about -0.08 and -0.10 for the employed and the inactive, respectively.

Using the above average elasticities and the estimated change in the number of nonunemployed job seekers, it is possible to quantify the crowding out effect imposed by non-unemployed job seekers on searchers from unemployment. The results suggest that, all else being equal, the lessening of crowding out (the number of job seekers from both employment and inactivity fell after 2007) would have lead to an overall 0.75 percentage 
point increase in the job finding rate of the unemployed at the end of the recession. For comparison, the job finding rate fell by about 9 percentage points in this period.

The contribution of the employed and the inactive job seekers to the lessening of the crowding out effect was roughly equal up until 2009. Thereafter, while the number of employed job seekers continued to fall, job seekers from out of the labor force started to recover, reducing their impact on the lessening of the crowding out effect.

\subsection{Search intensity vs. mismatch}

It was pointed out earlier that the estimated fractions of effective job seekers from employment and the inactivity are a product of the respective matching efficiency and the fraction of searchers in these two groups of individuals. Moreover, the unemployed may be searching with different intensity. From a policy perspective it is important to be able to decompose the two. If search behavior is partly driven by the state of the labor market, then stimulating the economy can increase search and improve the flow of workers into employment (even though it may do little in terms of improving true mismatch). This subsection briefly reviews the relatively scant evidence of workers' search behavior and discusses the implications for the estimated efficiencies of matching.

The main reason for the relatively small amount of research regarding workers' search intensity is a lack of high quality data. Exceptions are studies by Mukoyama, Patterson, and Sahin (2013) and DeLoach and Kurt (2012). ${ }^{28}$ The former paper uses data from the American Time Use Survey (ATUS) and from the CPS to try to quantify the extensive and intensive margins of search. They document that both margins increased in the Great Recession for the unemployed. DeLoach and Kurt (2012) use only the ATUS and find that search intensity of the unemployed is roughly a-cyclical. This is a combination of a decline in search intensity because of discouraging labor market conditions and an increase in search effort because of a fall in household wealth. ${ }^{29}$

The above-mentioned evidence suggests that search intensity of the unemployed remained the same or increased somewhat during the latest recession. This would mean that the presented estimates of mismatch of the unemployed are a lower bound. The reason is that an increase in search intensity compensates for a rise in mismatch, dampening the overall effect.

Regarding the search behavior of the employed and the inactive, the results in this paper suggest that the fraction of searching non-unemployed declined during the Great Recession. To the best of my knowledge, however, there is no independent empirical

\footnotetext{
${ }^{28}$ Several studies investigate the behavior of job seekers on job search websites, (see e.g. Brown and Matsa, forthcoming; Faberman and Kudlyak, 2014).

${ }^{29}$ Other studies using the ATUS, but focusing on different aspects of time use and job search include Aguiar, Hurst, and Karabarbounis (2013) and Krueger and Mueller (2010).
} 
evidence on the cyclicality of search intensity of employed and inactive individuals to compare these results with.

A rough proxy for the group of inactive individuals may be taken from data on marginally attached (discouraged) workers. ${ }^{30}$ Marginally attached workers have the highest transition probabilities into employment from the group of inactive individuals (see e.g. Barnichon and Figura, 2015). Moreover, if the estimated fractions of effective job seekers partly also capture cyclical changes in the fraction of searching individuals in the group of inactive, then we would expect a positive correlation between the cyclical component of the fraction of marginally attached (discouraged) workers in the group of inactive individuals and that of the estimated fraction of effective job seekers among the inactive. ${ }^{31}$ Indeed, the latter two correlations are 0.47 and 0.48 in the data, respectively. At the same time, however, such correlations must be taken only as indicative because the number of marginally attached and discouraged workers likely changes endogenously in response to higher mismatch.

While this section investigates how changes in search intensity can be linked to the estimated fluctuations in mismatch and the fraction of effective job seekers, the same arguments could be made for other types of heterogeneity. In general, treating the groups of unemployed, employed and inactive as homogeneous masks differences within these groups that could help identify the sources of mismatch fluctuations. ${ }^{32}$ While this is an important avenue of research, it is beyond the scope of this paper.

\section{Conclusion}

Several recent studies have documented variation in mismatch over the business cycle. The broad consensus, however, was that mismatch contributed at most $25-30$ percent to the unemployment increase in the latest recession and much less during normal times. This paper finds a much larger contribution of mismatch changes to unemployment fluctuations. Changes in mismatch are found to account for about one third of unemployment fluctuations over the business cycle on average and this contribution is as high as 49 percent during the Great Recession.

\footnotetext{
${ }^{30}$ Marginally attached workers are those that want a job and have actively searched in the past twelve months, but have not searched in the last four weeks. Discouraged workers are those who report "discouragement" as the reason for stopping to search for a job. Reasons for discouragement include the belief that there are no jobs available for them, they could not find work, they lack the necessary schooling, skills or experience, or they perceive some type of discrimination in the workplace. Kudlyak and Lange (2014) show, however, that even among this group there is large heterogeneity in job finding rates which can be traced back to the individual labor force status histories.

${ }^{31}$ Discouraged workers account for about $30 \%$ of marginally attached individuals (and for about $1 \%$ of all inactive individuals).

${ }^{32}$ Hall and Schulhofer-Wohl (2013) go a step further in this respect by categorizing individuals not into three but nine labor market states.
} 
The reason for the different results stems from an omitted variable bias. Existing studies largely ignore job seekers from outside unemployment, mainly due to data limitations. This approach remains valid for estimating the aggregate matching function (and mismatch) only if the number of unemployed and non-unemployed job seekers are perfectly correlated over the business cycle. Using an unobserved components model to uncover the latent fraction of job seekers among the group of employed and inactive individuals reveals that such a property does not seem to hold in the U.S. data. The resulting estimates of matching efficiency fluctuate considerably more than was previously thought and they in turn have a stronger influence on unemployment dynamics.

The analysis in this paper therefore highlights fluctuations in mismatch as a crucial determinant of changes in unemployment. Looking deeper into the sources of changes in mismatch and separating them from fluctuations in search intensity is therefore important for understanding unemployment fluctuations and as such is an interesting avenue for future research.

\section{Acknowledgements}

I thank my editor Matthias Doepke and two anonymous referees for greatly improving this paper. I also thank Christian Bayer, Wouter den Haan, Gregory Jolivet, Philip Jung, Sabine Klinger, Keith Kuester, Christian Merkl, Aysegul Sahin, Vincent Sterk, Emily and Robert Swift, Felix Wellschmied, Fangbo Yang and seminar participants at the University of Barcelona, Bonn, Bristol and Nürnberg for their comments and suggestions. I gratefully acknowledge the financial support of the Daimler und Benz Foundation. 


\section{References}

Aguiar, M., E. Hurst, and L. Karabarbounis (2013): "Time Use during the Great Recession," American Economic Review, 103(5), 1664-96.

Barlevy, G. (2011): "Evaluating the Role of Labor Market Mistmatch in Rising Unemployment," Economic Perspectives, Federal Reserve Bank of Chicago.

Barnichon, R. (2010): "Building a Composite Help-Wanted Index," Economics Letters, $109(3), 175-178$.

Barnichon, R., And A. Figura (2015): "Declining Desire to Work and Downward Trends in Unemployment and Participation," NBER Macroeconomics Annual.

— (forthcoming): "Labor Market Heterogeneity and the Aggregate Matching Function," American Economic Journal: Macroeconomics.

Boersma, L., And J. VAn OURS (1999): "Job searchers, job matches and the elasticity of matching," Labour Economics, 6, 77-93.

Borowczyk-Martins, D., G. Jolivet, and F. Postel-Vinay (2013): “Accounting for endogeneity in matching function estimation," Review of Economic Dynamics, 16, $440-451$.

Brown, J., And D. Matsa (forthcoming): "Boarding a Sinking Ship? An Investigation of Job Applications to Distressed Firms," Journal of Finance.

Cogley, T., and T. Sargent (2005): "Drifts and Volatilities: Monetary Policies and Outcomes in the Post WWII US," Review of Economic Dynamics, 8(2), 262-302.

Davis, S., J. Faberman, J. Haltiwanger, and I. Rucker (2008): "Adjusted Estimates of Worker Flows and Job Openings in JOLTS," NBER Working Paper No. 14137.

DeLoach, S., And M. Kurt (2012): "Discouraging Workers: Estimating the Impacts of Macroeconomic Shocks on the Search Intensity of the Unemployed," mimeo.

Dickens, W. T. (2011): "A New Method for Estimating Time Variation in the NAIRU," mimeo.

Elsby, M., R. Michaels, and G. Solon (2009): "The Ins and Outs of Cyclical Unemployment," American Economic Journal: Macroeconomics, 1(1), 84-110. 
Faberman, J., And M. Kudlyak (2014): "The Intensity of Job Search and Search Duration," Richmond FED Working Paper No. 14-12.

HALl, R. (2005): "Employment Fluctuations with Equilibrium Wage Stickiness," American Economic Review, 95(1), 50-65.

Hall, R., and S. Schulhofer-Wohl (2013): "Measuring Matching Efficiency with Heterogeneous Jobseekers," mimeo,Hoover Institution, Stanford University,.

Hornstein, A., And M. KudlyaK (2015): "Estimating Matching Efficiency with Variable Search Effort," mimeo.

Jolivet, G. (2009): "A longitudinal analysis of search frictions and matching in the U.S. labor market," Labour Economics, 16, 121-134.

Krueger, A., And A. Mueller (2010): "Job Search and Unemployment Insurance: New Evidence from Time Use Data," Journal of Public Economics, 94, 298-307.

Kuang, K., and R. Valletta (2010): "Extended Unemployment and UI Benefits," Federal Reserve Bank of San Francisco, Economic Letter 2010-12.

Kudlyak, M., and F. Lange (2014): "Measuring Heterogeneity in Job Finding Rates Among the Nonemployed Using Labor Force Status Histories," Richmond FED Working Paper No. 14-18.

Lubik, T. A. (2011): "The Shifting and Twisting Beveridge Curve: An Aggregate Perspective," mimeo.

Mukoyama, T., C. Patterson, and A. Sahin (2013): "Job Search Behavior over the Business Cycle," mimeo.

NAGYpÁL, E. (2009): "What can we learn about firm recruitment from the job openings and labor turnover survey?," In Dunne, T., Jensen, J.B., Roberts, M.J., Producer dynamics: New evidence from micro data, University of Chicago Press, Chicago.

Petrongolo, B., and C. Pissarides (2001): "Looking into the black box: A survey of the matching function," Journal of Economic Literature, 39, 390-431.

Primiceri, G. (2005): "Time Varying Structural Vector Autoregressions and Monetary Policy," Review of Economic Studies, 72, 821-852.

Ravn, M., and H. Uhlig (2002): "On Adjusting the Hodrick-Prescott Filter for the Frequency of Observations," Review of Economics and Statistics, 84(2), 371-380. 
Rogerson, R., And R. Shimer (2010): "Search in macroeconomic models of the labor market," NBER Working Paper no. 15901.

Sahin, A., J. Song, G. Topa, And G. Violante (2014): "Mismatch Unemployment," American Economic Review, forthcoming.

SedláčEK, P. (2014): "Match Efficiency and Firms' Hiring Standards," Journal of Monetary Economics, 62(2), 123-133.

Shimer, R. (2005): "The Cyclical Behavior of Equilibrium Unemployment and Vacancies," American Economic Review, 95(1), 25-49.

Sterk, V. (2015): "Home equity, Mobility and Macroeconomic Fluctuations," Journal of Monetary Economics, 74, 16-32.

Veracierto, M. (2011): "Worker Flows and Matching Efficiency," Economic Perspectives, Federal Reserve Bank of Chicago. 